\title{
Digital business model innovation: toward construct clarity and future research directions
}

\author{
Matthias Fabian Gregersen Trischler $^{1} \cdot$ Jason Li-Ying ${ }^{1}$
}

Received: 31 March 2021 / Accepted: 26 November 2021 / Published online: 4 January 2022

(c) The Author(s) 2021

\begin{abstract}
In times of unprecedented change related to the ongoing digital transformation of business and society at large, a pressing contemporary management challenge is recognizing and translating these changes into digital business model innovation (DBMI). Academia potentially has much to offer in aiding this managerial challenge, yet research in the field remains vague with regard to what DBMI is. We detect conceptual ambiguity among scholars as a bottleneck that prevents advancements in the field of DBMI research. In this article, we aim to trace the foundation of key attributes of the DBMI concept and propose a novel definition. Our insights are based on a targeted, state-of-the-art literature review of 57 publications. We conclude with an exploration of avenues for future research, which we closely link to the broader fields of strategic management, information systems, and organization studies, thereby exposing the issue of DBMI to a wider audience. Overall, we aim to make a significant step toward construct clarity in DBMI research.
\end{abstract}

Keywords Digitalization · Business model $\cdot$ Strategy $\cdot$ Digital transformation · Dynamic capability

JEL Classification M10 $\cdot$ M19 $\cdot$ O30

\section{Introduction}

Digitalization is affecting almost all industries by creating opportunities and challenges for established firms, large born digitals, and smaller start-ups (Rachinger et al. 2018; Volberda et al. 2021). Industry players as well as consumers are

Jason Li-Ying

yinli@dtu.dk

Matthias Fabian Gregersen Trischler

mattri@dtu.dk

1 Centre for Technology Entrepreneurship, Technical University Denmark, Building 371,

2800 Kgs. Lyngby, Denmark 
becoming increasingly smart through the proliferation of digital technologies, such as those related to the Internet of Things, and the acceptance and use of affordable mobile devices and personal computers (Fichman et al. 2014; Parida et al. 2019; Venkatesh et al. 2019). Competition is intensifying, and the pace of change is accelerating as more agile start-ups make use of the low entry barriers in digital markets and enter industries that were dominated by incumbents (Loebbecke and Picot 2015; Ehret and Wirtz 2017; Teece and Linden 2017). The emergence and diffusion of digital technologies have further led to an explosion of available data, making data analytics and machine learning capabilities important competitive advantages for companies (Hanelt et al. 2020). These examples of the impact of digitalization show that information technology can no longer be viewed as a subordinate support function, but rather that digital needs to be perceived as an integral part of the business and organization (Yoo et al. 2010; El Sawy and Pereira 2013; Matt et al. 2015).

Managers have acknowledged the central role of digital and prioritized digital transformations on their leadership agendas (Warner and Wäger 2019). Nevertheless, many digital transformations fail because firms are unable to leverage the potential benefits of their significant investments in digital technologies (Linde et al. 2021). A predominant reason for this digital paradox is that investments in digital technologies alone, even though they might lead to technological superiority, do not guarantee success (Vial 2019; Volberda et al. 2021).

Indeed, digital transformation is more a managerial issue than it is a technological one ( $\mathrm{Li}$ et al. 2017). To profit from digital technologies and to remain competitive in this complex and ambiguous digital business context (Schoemaker et al. 2018), firms need to design, develop, and implement digital business model innovation (DBMI) (Berman 2012; Veit et al. 2014). A business model essentially describes the business logic of a firm and how it creates, delivers, and captures value (Teece and Linden 2017). DBMI thus involves changes in the value proposition, value delivery, and/or value capture of firms (Parida et al. 2019). The need to treat DBMI as an individual phenomenon that differs radically from earlier forms of business model innovation has been strongly advocated in the literature (Fichman et al. 2014; Nambisan 2017; Lanzolla et al. 2020a; Volberda et al. 2021).

However, despite its importance in the digital transformation of firms, research on DBMI is still in its infancy, and the phenomenon remains poorly understood (Rachinger et al. 2018; Aagaard 2019; Parida et al. 2019; Li 2020). A major concern in this respect is the low level of construct clarity regarding the concept of DBMI (Venkatesh et al. 2019), as a common definition of DBMI is missing (Schallmo and Williams 2018; Bican and Brem 2020). Scholars have regularly criticized the lack of consistent terminology (Blaschke et al. 2016; Standing and Mattsson 2018) or the persistent ambiguity (Veit et al. 2014; Kohli and Melville 2019), and have emphasized that confusion regarding the construct of DBMI is paramount (Bican and Brem 2020). In order to advance our understanding of DBMI and allow further knowledge accumulation to assist managers and practitioners in their digital transformation endeavors, a high level of construct clarity for DBMI is thus needed (Foss and Saebi 2018; Gong and Ribiere 2021). However, there is a lack of attempts to define the concept of DBMI amongst scholars (Martín-Peña et al. 2018). 
We contribute to this gap in the literature by proposing a novel definition for the concept of DBMI. Guided by our research question — what defines DBMI? — we conduct an extensive state-of-the-art literature review of 57 articles from major journals as well as selected book chapters from multiple fields to uncover key attributes that build the foundation of DBMI. We scrutinize the new definition of DBMI for its ability to advance future research on the topic. Overall, we aim to make a significant step toward construct clarity in DBMI research by reviewing the state of the art in the field, proposing a novel definition, and outlining directions for future research.

The remainder of the paper is structured as follows. The next section briefly introduces our approach to conducting this literature review. We then argue for the importance of construct clarity, followed by a critical assessment of extant definitions in the field. We then discuss a set of attributes in depth and propose a novel definition of DBMI. Finally, we conclude with a discussion intended to guide future research.

\section{Method}

The value of review articles is well established in management science (Breslin et al. 2020; Kraus et al. 2020). We follow the methodology of Wolfswinkel et al. (2013), who propose a five-stage approach to rigorously reviewing the literature: (1) defining the scope of the review, (2) searching the literature, (3) selecting the final sample, (4) analyzing the corpus, and (5) presenting the findings. Below, we will discuss each of these stages in more detail. Figure 1 visualizes our approach.

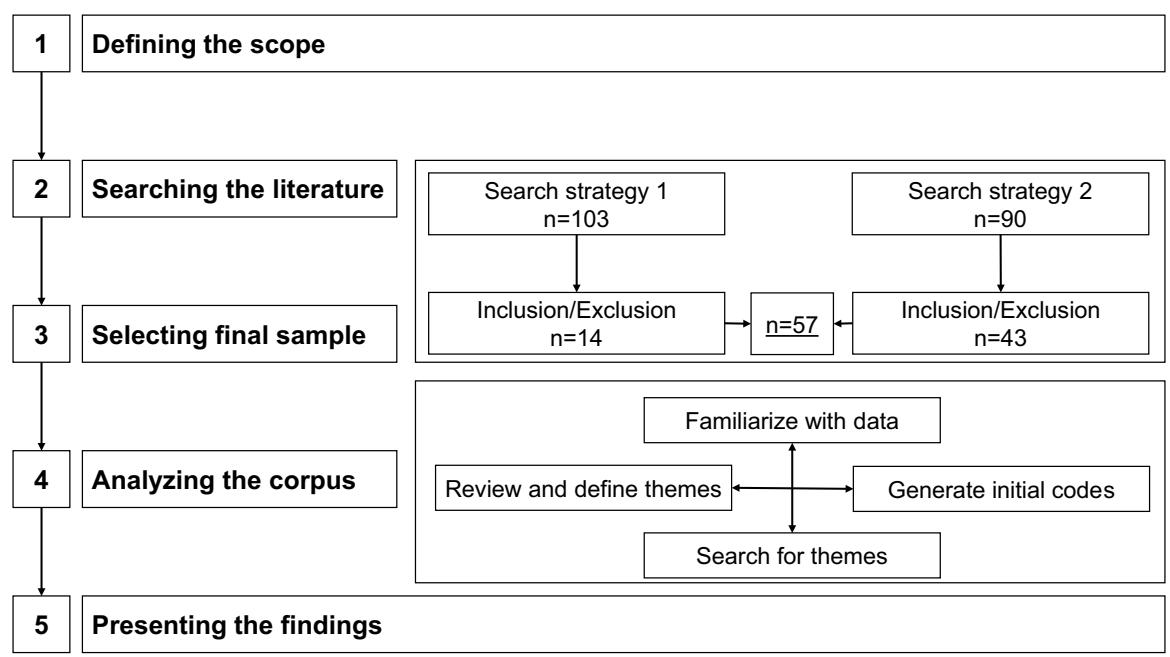

Fig. 1 Five-stage approach to reviewing literature 


\subsection{Defining the scope of the review}

The scope of this article is a state-of-the-art literature review of the concept of DBMI. According to Grant and Booth (2009), a state-of-the-art review is particularly useful when addressing current matters. In contrast to more systematic approaches, which aim to provide exhaustive overviews of literature, a state-ofthe-art review intends to carry out a comprehensive search of the current literature (Grant and Booth 2009). The limitation of this approach is that some older relevant articles may have escaped our attention. However, as the concept of DBMI is relatively new (El Sawy and Pereira 2013; Martín-Peña et al. 2018), we expect the risk of missing older articles to be minimal.

\subsection{Searching the literature}

To search the literature, we followed a two-pronged approach. First, following the strategy proposed by Foss and Saebi (2017), we searched the EBSCO Business Source Premier database for academic articles containing the terms "digital" AND "business model innovation" in their titles, abstracts, or keywords (Boolean phrase, English, limited to peer-reviewed work in academic journals, from 2005 to 2020). This approach yielded 103 unique publications. Second, we followed Webster and Watson (2002), who suggest starting a literature search by reviewing leading journals in the field and then moving backwards (i.e., to references) and forwards (i.e., to citations).

To identify the leading journals, we relied on Wirtz et al. (2016), who state that the business model construct is primarily studied from three perspectives: technology, organization, and strategy. For each of these perspectives, we identified two subcategories that seemed relevant to this inquiry: technology and innovation management, information management, strategic entrepreneurship and small business management, organizational science, strategy, and management. Based on this overview of the relevant subcategories, we selected the three top journals in each, according to the Academic Journal Guide 2018 by Chartered ABS as a starting point for our second search strategy. Furthermore, we included three top practitioner journals (Harvard Business Review, California Management Review, and MIT Sloan Management Review) as well as selected review or theory development journals (Academy of Management Review, Business Strategy Review). This final category is important as good reviews build on existing reviews (Parmigiani and King 2019). For this approach, we used slightly adapted search criteria as we also included books and book chapters. This alternative search strategy resulted in another 90 potentially relevant, unique publications. In total, we thus collected 193 unique publications as the initial sample. This literature review was conducted from October 2020 to March 2021. 


\subsection{Selecting the final sample}

To select the final sample, we applied a strict set of criteria for quality appraisal. First and foremost, given the broad nature of the concept under review, a key criterion for the final sample was that DBMI is integrally discussed in the study (George and Bock 2011; Lambert and Davidson 2013). Furthermore, all the publications had to be in English, printed between 2005 and 2020, and published in either peer-reviewed journals or peer-edited books. Keynotes, opinion pieces, conference papers, and workshop notes were excluded from this review. The final selection of the sample was conducted by the two authors independently to minimize bias, and divergences were discussed and resolved. In sum, we included 57 unique publications in this state-of-the-art literature review (see Table 1).

\subsection{Analyzing the corpus}

The analysis of the corpus was inspired by Braun and Clarke's (2006) iterative approach to thematic analysis, which comprises several phases, including familiarizing yourself with the data, generating initial codes, searching for themes, and reviewing and defining themes. In a first step, we carefully read all the selected studies in the final sample. Subsequently, we coded interesting features in the corpus in an inductive fashion (Patton 1990). Again, the two authors performed this crucial step of the analysis independently (Kraus et al. 2020). We then collated codes into latent themes or attributes, which compose the foundation of our novel definition. Throughout the analysis of the corpus, five attributes for defining DBMI emerged, including purposeful/deliberate, novel/non-trivial, dynamic/evolving, components/ elements, and digital technology/digitalization. These will be further discussed below.

\subsection{Presenting the findings}

While the findings will be discussed in more detail below, here we briefly present some relevant facts about the corpus of this study. Most of the studies in our sample were published in the past five years (2016-2020: 44 publications). This is promising as it indicates a strong and growing interest in the field. However, it also urges us to increase the clarity of the construct so that research efforts do not branch off in various unconnected directions.

It becomes evident that our contribution is relevant and timely when looking at the quantity and diversity of extant definitions. Table 2 presents an overview of the explicit or implicit use of the key concepts related to DBMI. Throughout the analysis, we found that only seven studies in our sample explicitly provided a definition for the concept of DBMI, yet with varying degrees of clarity and detail (see below for a more granular discussion). The majority of the reviewed articles have a strong foundation in traditional business model research, explicitly defining the concept or relying on the well-established discourse (e.g., Teece 2010; Massa et al. 2017). Interestingly, only a few studies explicitly define the concept of digital business 


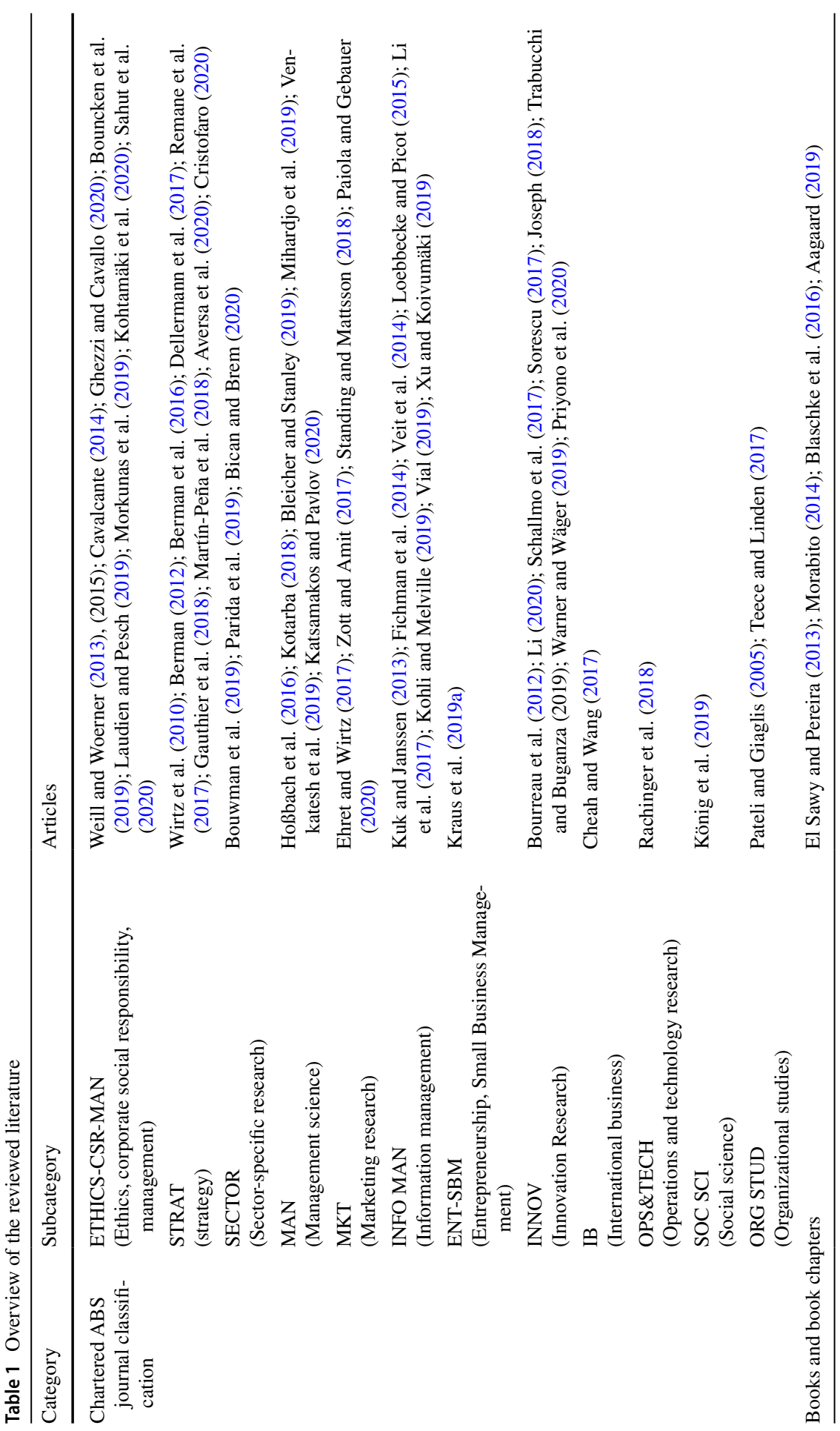


models or related digital terms, such as digital innovation, digital(ization), or digital transformation. This is a critical finding because it shows that the impact of digital on business model innovation is still fuzzy (Rachinger et al. 2018) and that a digital conundrum prevails in the literature where key concepts lack construct clarity (Bican and Brem 2020). Such a lack of focus on digital is problematic, however, as simply adding a few digital features when theorizing about innovative business models leads to a horseless carriage fallacy (El Sawy and Pereira 2013). In other words, the digital era provides a radically different context, which is incomparable to the previous environments in which generic business model innovation has been examined (Nambisan 2017; Volberda et al. 2021). Yet, researchers at the intersection of digital and business model innovation mostly fail to clearly and explicitly define the concept of DBMI (Schallmo et al. 2017; Martín-Peña et al. 2018).

\section{The importance of construct clarity}

An important precondition for construct clarity is a precise and generally accepted definition. This is important as constructs develop in the researcher's mind and are heavily influenced by their context, background, and social setting. Definitions must thus be carefully designed (Wacker 2004) and require considerable skill in terms of crafting (Suddaby 2010) to clearly represent the abstract concept.

Here, we highlight Suddaby's (2010) illuminating work, which emphasizes that a good definition needs to accomplish three tasks: (1) The definition should effectively capture the essential properties and characteristics of the concept or phenomenon under consideration; (2) a good definition should avoid tautology and circularity; and (3) a good definition should be parsimonious, that is it should try to capture as concisely as possible the essential characteristics of a phenomenon or concept. In other words, researchers should avoid maximalist and minimalist definitions, as either extreme of including too much or too little information in a definition relative to theoretical goals can cause problems (Munck and Verkuilen 2002; Goertz 2006). Maximalist definitions include too many attributes — or intensions - thereby decreasing the number of instances that can be identified (extensions). At one extreme, a concept becomes an ideal type when the concept has no empirical referents because it has been overburdened with attributes (Goertz 2006). At the other extreme, minimalist definitions include too few attributes, resulting in almost all cases automatically becoming instances, which weakens the explored phenomenon. In these cases, adding relevant attributes to a definition enhances construct clarity.

However, there is no hard and fast rule that can be used to determine what attributes must be included in a definition of a certain concept (Munck and Verkuilen 2002). Generally speaking, however, an optimal definition - or effective constructis one in which researchers have identified the exact number of attributes that define a concept accurately and precisely in a concise manner but in a way that allows broad audiences to understand and participate in the discourse (Suddaby 2010). For research fields in their early stages that are characterized by exploratory efforts, it 
10

M. F. G. Trischler, J. Li-Ying

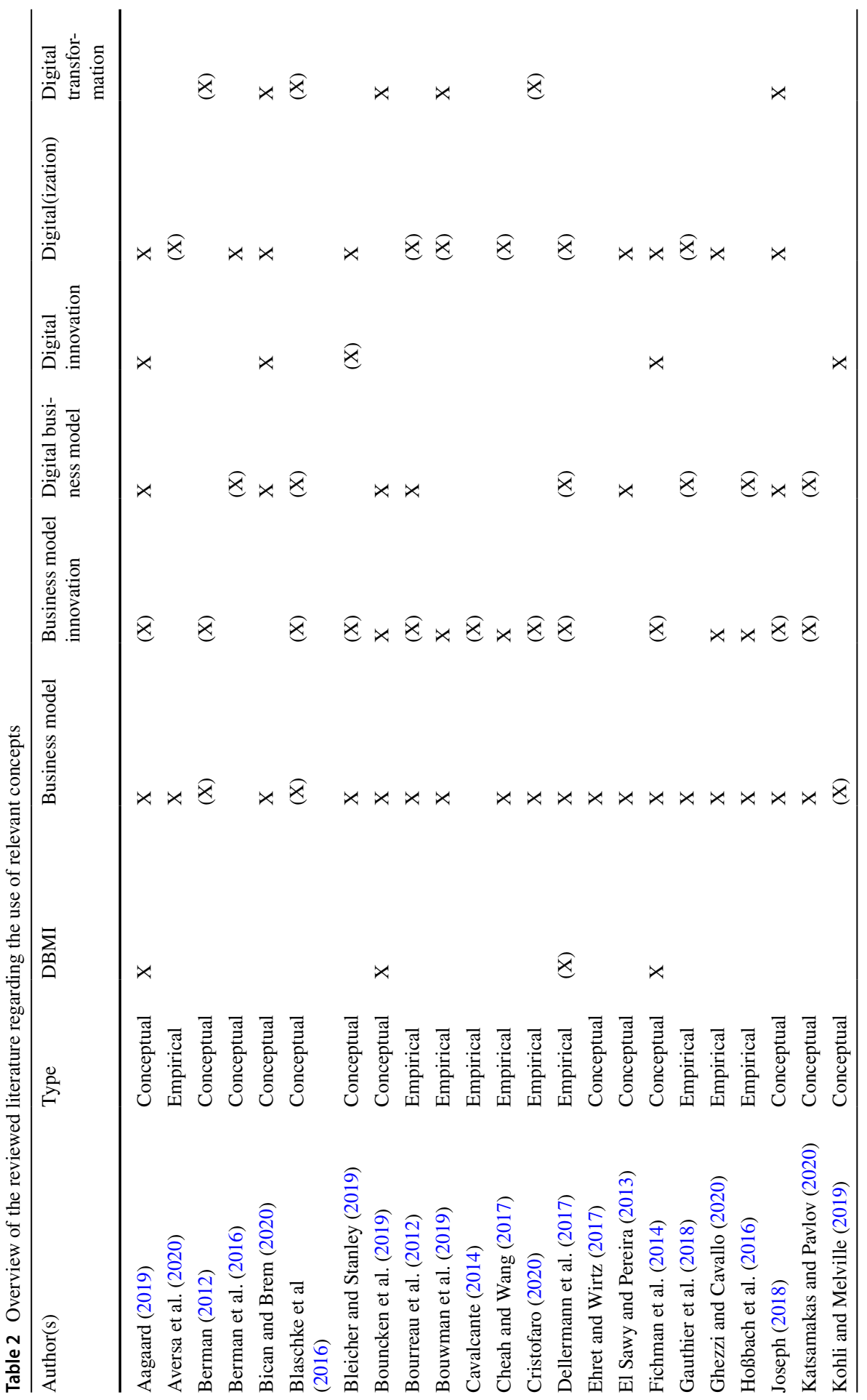

Springer 
Digital business model innovation: toward construct clarity...

11

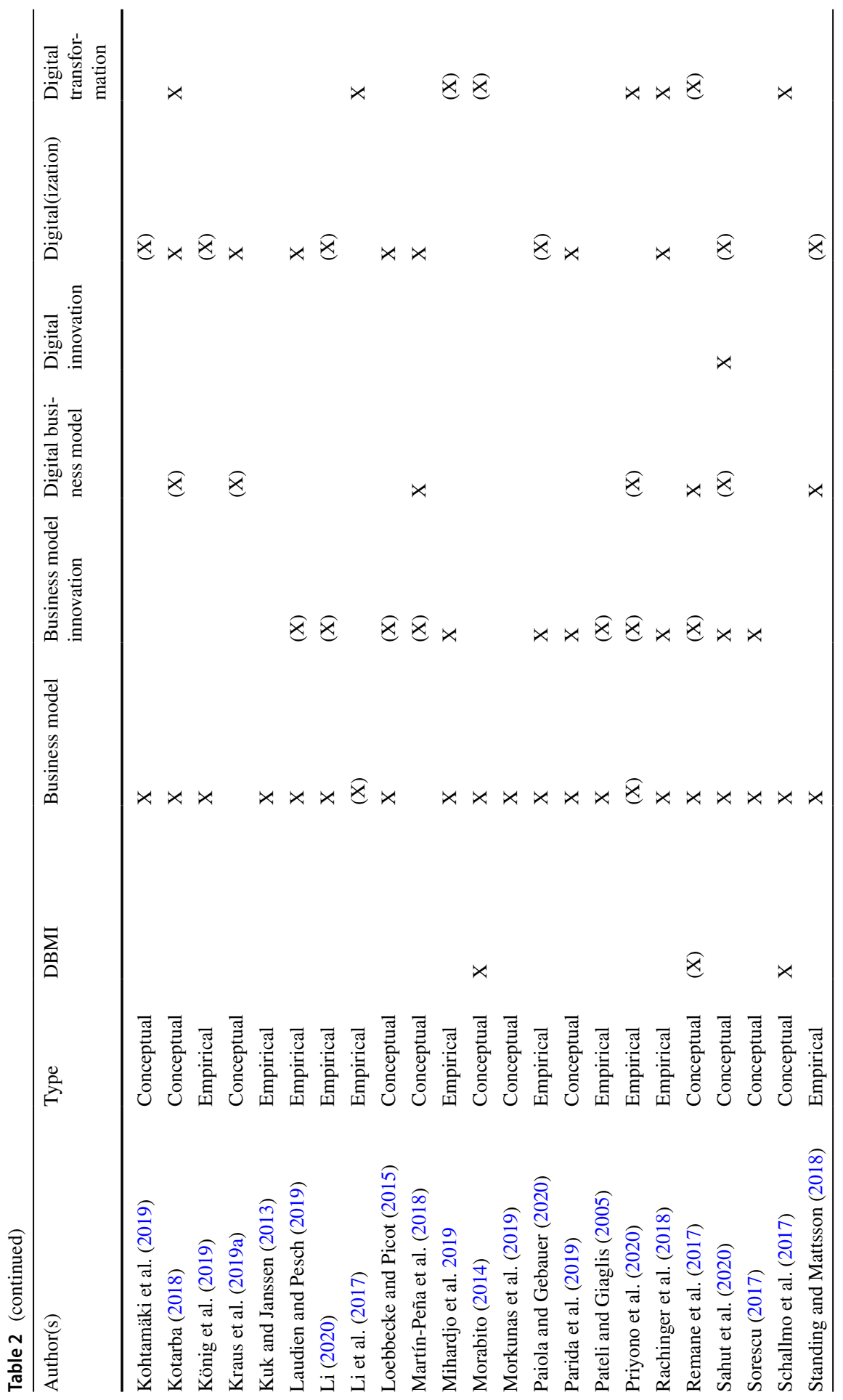

Springer 
12

M. F. G. Trischler, J. Li-Ying

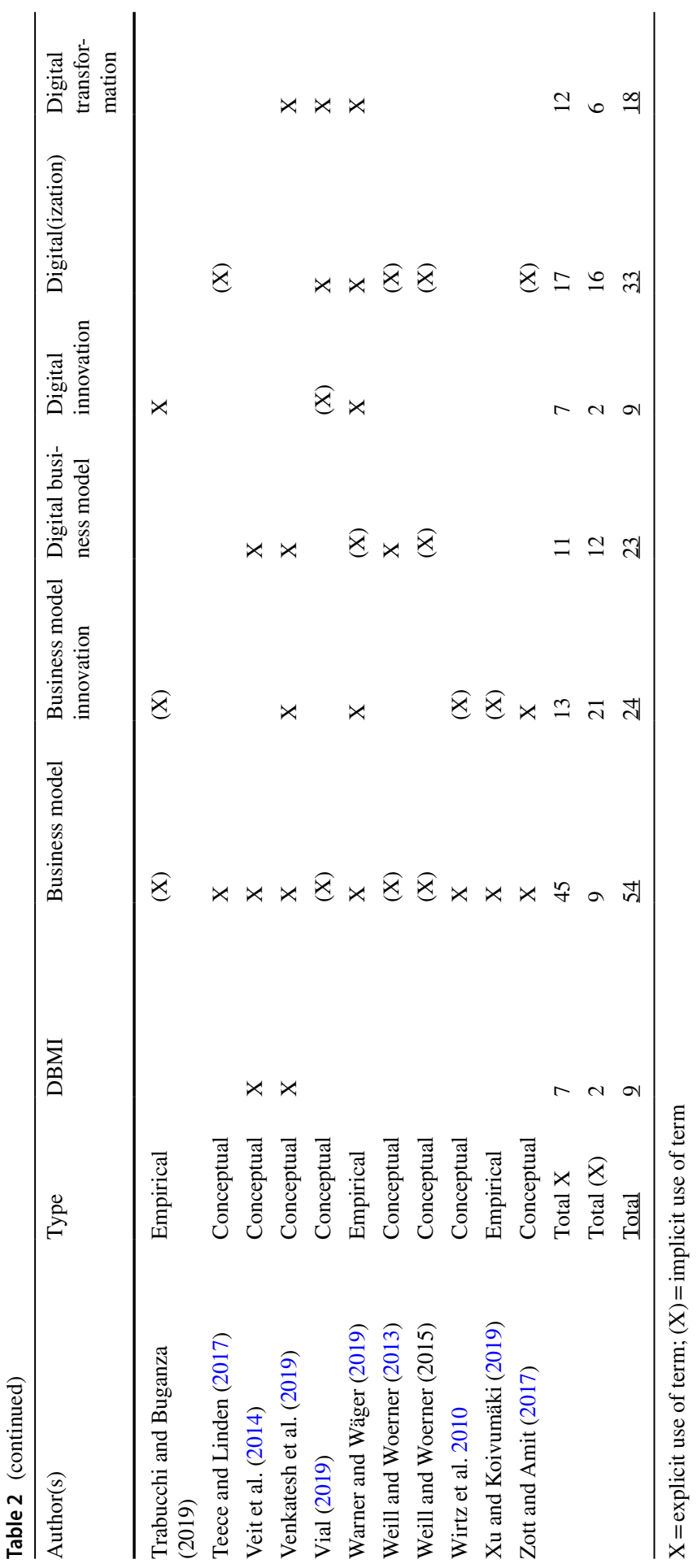

Springer 
has been argued that rather broad definitions leaning toward the minimalistic end of the spectrum are more suitable (Sharma and Chrisman 1999).

In sum, we argue that construct clarity based on a precise definition is crucial to advance research on DBMI. We suggest that a rather broad definition, leaning toward the minimalistic end of the spectrum, is needed for DBMI, given the nascent stage of research. With this understanding, below we review and discuss extant definitions that we identified through the literature review. Subsequently, we propose a novel definition and its foundation, which aims to contribute to the construct clarity of DBMI.

\section{Extant definitions of DBMI}

In our corpus, we identified a total of seven definitions of DBMI. Given our overall sample size of 57 academic publications, this relatively small proportion confirms the finding of Martín-Peña et al. (2018), who highlighted the lack of attempts to define the concept. Most other authors relied predominantly on an explicit definition of the business model construct or referred to the well-established discourse on business model research. Fewer studies explicitly defined business model innovation and discussed the concept in light of digital transformation. However, in most cases, the terms related to digital, such as digital innovation, digital(ization), and digital transformation, were not clearly defined, confirming the digital conundrum criticized in the literature (Bican and Brem 2020). Table 3 lists all the identified definitions.

Based on our understanding of construct clarity (see above), we now critically assess the extant definitions. We make the following observations. First, some of the proposed definitions use unclear terms-terms that are also lacking construct clarity, such as digital technology (Veit et al. 2014; Aagaard 2019), digital marketplace (Venkatesh et al. 2019), or personalized products (Morabito 2014). Looking at the preconditions of good definitions as prescribed by Suddaby (2010), we notice that some of these descriptions do not meet the criteria of effectively capturing the essential properties of a construct. When attributes of low clarity are used to define a concept, the definition leaves as many questions as it provides answers. Second, we have argued for a rather broad definition above, given the nascent stage of DBMI research, where much remains uncharted territory (Aagaard 2019). Reviewing extant definitions, we notice that many of them are overburdened with various attributes, sometimes to the extreme (e.g., Schallmo et al. 2017). Third, as argued by Suddaby (2010), a good definition is parsimonious and achieves definitional accuracy while being generally communicable. In other words, a concise definition is manageable and applicable not only for academia but also — and in particular-for practitioners. Yet, some of the definitions in our sample seem overly complex and cumbersome, which can lead to rejection from practitioners. In fact, the differences in understanding business model innovation from an academic and practitioner perspective have been critically analyzed in the literature (DaSilva and Trkman 2014; DaSilva 2018). A broad yet concise definition can therefore contribute to 
unifying the practical and academic understanding of DBMI. Finally, we notice that, in many cases, the definitions seem unconnected. That is, authors of more recent contributions did not—or did only to a limited degree-draw on earlier definitions.

Considering these critical reflections, our aim is to build on existing definitions to propose a novel definition for DBMI that resolves the conceptual issues laid out above. To do so, we analyzed the corpus of literature to identify common attributes and similarities of how scholars use the DBMI construct (even when not explicitly defined). In the following section, we thus discuss and explain the foundation for each of these attributes.

\section{Foundations of DBMI attributes}

As described above, through a thematic analysis, five broad attributes emerged as being frequently used by DBMI scholars in the reviewed literature: purposeful, non-trivial, dynamic, change in key business model elements, and digitalization. These attributes form the backbone of our novel definition and will be discussed below.

\subsection{DBMI is purposeful and deliberate}

The literature review revealed a debate about whether DBMI is deliberate and purposeful or takes place in a more ad hoc and spontaneous fashion (Cavalcante 2014; Kohli and Melville 2019). Kotarba (2018), for instance, states that changes in a firm's digital business model can either be voluntary, where the firm takes a proactive role in shaping its future digital business model, or reactive, where unplanned and unexpected changes adversely affect the business model and call for restructuring or emergency operations. The majority of scholars in our sample, though, see DBMI as a deliberate act, initiated by a strategic decision of an entrepreneur or manager (Morabito 2014; Li et al. 2017; Teece and Linden 2017; Bouwman et al. 2019; Aversa et al. 2020; Priyono et al. 2020), sometimes based on detailed (digital) scenario planning (Pateli and Giaglis 2005; Warner and Wäger 2019).

This argument is further supported by the manifold DBMI approaches proposed in our sample. These range from rather generic digital innovation processes (Fichman et al. 2014) and multi-step approaches (Berman 2012; Berman et al. 2016; Blaschke et al. 2016; Bleicher and Stanley 2019) to detailed methodologies for identifying DBMI in traditional industries (Remane et al. 2017) and comprehensive roadmaps for digitally transforming business models (Schallmo et al. 2017). What unifies these approaches is an initial emphasis on analyzing, planning, and envisioning future DBMI, which suggests strategic intent.

Seeing (digital) business model innovation as deliberate or purposeful is in line with a strong community of strategy scholars who view business models (and their innovation) as distinct phenomena interlinked to strategy (Teece 2010; Klang et al. 2014; Gassmann et al. 2016). Casadesus-Masanell and Ricart (2010), for instance, have 
Table 3 Extant definitions of DBMI

\begin{tabular}{|c|c|}
\hline Definition & Source \\
\hline $\begin{array}{l}\text { How digital business models can exploit and leverage the scope of digital } \\
\text { technologies, scale up the trans-functional impacts of digital enablement, and } \\
\text { adapt to the speed and business dynamics of the digital marketplace }\end{array}$ & Venkatesh et al. (2019) \\
\hline $\begin{array}{l}\text { How companies adopt and deploy digital technologies and business models to } \\
\text { improve performance quantifiably }\end{array}$ & Aagaard (2019) \\
\hline $\begin{array}{l}\text { Digital technologies have a significant impact on all dimensions, value creation, } \\
\text { value capture, and value proposition. Digitalized business models might use } \\
\text { very novel or less novel digital technology, but the necessary condition is that } \\
\text { all dimensions use digital technologies, not only certain activities of the firm. } \\
\text { We are well aware that the term significant is fuzzy. Yet, the diverse digital } \\
\text { technology and the magnitude of diverse uses make considerations about } \\
\text { certain degrees unrealistic }\end{array}$ & Bouncken et al. (2019) \\
\hline $\begin{array}{l}\text { The digital transformation of business models relates to individual business } \\
\text { model elements, the entire business model, and value-added chains, as well } \\
\text { as the networking of different actors in a value-added network. The degree of } \\
\text { the digital transformation includes incremental (marginal) as well as radical } \\
\text { (fundamental) changes in a business model. The reference unit with regard to } \\
\text { the level of novelty is primarily the customer, but a digital transformation can } \\
\text { also affect its own business, partners, industry, and competitors. Within the } \\
\text { digital transformation of business models, enabler(s) and technologies (e.g., } \\
\text { big data) are used to generate new applications or services (e.g., on-demand } \\
\text { prediction). These enablers require skills that enable data collection and } \\
\text { exchange as well as the ability to analyze, calculate, and evaluate options. } \\
\text { The evaluated options are used to initiate new processes within the business } \\
\text { model. The digital transformation of business models is based on an approach } \\
\text { with a sequence of tasks and decisions that are related to one another in a } \\
\text { logical and temporal context. It affects four target dimensions: time, finance, } \\
\text { space, and quality }\end{array}$ & Schallmo et al. (2017) \\
\hline $\begin{array}{l}\text { A significantly new way of creating and capturing business value that is embod- } \\
\text { ied in or enabled by IT }\end{array}$ & Fichman et al. (2014) \\
\hline $\begin{array}{l}\text { The creation and utilization of new knowledge (which can be technological, } \\
\text { organizational, or market-related) that enables a company to benefit from } \\
\text { the disruptive attributes of the Internet in order to design and implement an } \\
\text { innovative system to provide customers with highly personalized products and } \\
\text { services targeted to the needs of the customer themselves }\end{array}$ & Morabito (2014) \\
\hline $\begin{array}{l}\text { A business model is digital if changes in digital technologies trigger fundamen- } \\
\text { tal changes in the way business is carried out and revenues are generated }\end{array}$ & Veit et al. (2014) \\
\hline
\end{tabular}

argued that a firm's business model is the result of strategic decisions and a reflection of its realized strategy. Vial (2019: 124) further finds that the majority of works related to digital transformation treat the phenomenon as endogenous, where "initiatives are purposefully created to respond to opportunities afforded by digital technologies." From an entrepreneurship theory perspective, the support for this attribute ("purposeful") is less clear. Some scholars argue that entrepreneurial processes can either take the shape of causation or effectuation (Xu and Koivumäki 2019). The first refers to processes that take a particular effect as a given and focus on selecting the means to create that effect. The latter, in contrast, takes a set of means as a given and focuses on selecting from 
the possible effects that can be created with that set of means (Sarasvathy 2001). However, scholars in the field of DBMI have connected these two seemingly distinct processes. Cavalcante (2014) introduces a pre-stage to DBMI that is characterized by the processes of experimenting and learning and can subsequently lead to actual DBMI. In sum, we argue that DBMIs do not happen out of thin air, even when the approach is more experimental; thus, the attribute of purposeful can be used to define the concept.

\subsection{DBMI is novel and non-trivial}

The issue of what characterizes an innovation is decades old. There is a plethora of famous propositions to resolve the issue of how to measure novelty, the most wellknown probably being the distinction between new to the world and new to the firm (see the OECD's Oslo Manual). Some authors of the reviewed literature follow the maximal perspective that DBMI has to be new to the world to be considered an innovation (Zott and Amit 2017; Sahut et al. 2020). Others, however, take a more nuanced approach to the degree of novelty of DBMI (Bouncken et al. 2019). Some argue, for instance, that the new digital business model has to be difficult to imitate (Ghezzi and Cavallo 2020), that a major part of the business has to be transferred into digital (Kraus et al. 2019a), or that digital denotes companies that rely substantially on the Internet (Standing and Mattsson 2018). In line with this nuanced perspective, Fichman et al. (2014) add the notion of significance to their definition of DBMI, and subsequently, Rachinger et al. (2018) discuss how companies need to significantly adapt their business models to the opportunities provided by digital transformation.

More support for this nuanced perspective comes from Warner and Wäger (2019), who suggest that for most incumbents the creation of truly new digital business models is unlikely. In fact, the question of what a new business model entails is extensively discussed by $\mathrm{Li}$ (2020), who concluded that truly novel (digital) business model innovations are hard to come by, as precedents almost always exist. The authors of our reviewed literature therefore often identify different levels of digitalization with regard to business model innovation (Rachinger et al. 2018; Kohtamäki et al. 2019; Kraus et al. 2019a). For instance, Li (2020) and Berman (2012) similarly describe a continuum of how firms can enhance, extend, and transform or redefine the value proposition through digitalization. In line with Foss and Saebi's (2017) discourse on non-triviality in business model innovation per se, we therefore suggest that DBMIs are novel in a non-trivial manner, thereby excluding simple modifications, such as adding an online presence as a marketing tool.

\subsection{DBMI is dynamic}

Digitalization creates a highly dynamic environment. Firms are constantly challenged with vulnerabilities and opportunities because of the ubiquitous proliferation of digital technologies, adaption to the digital culture by customers, and strong competition due to low entry barriers in digital markets (Weill and Woerner 2013; Veit et al. 2014; Venkatesh et al. 2019). Some describe this dynamic environment 
as VUCA: volatile, uncertain, complex, and ambiguous (Schoemaker et al. 2018; Warner and Wäger 2019).

It is therefore no surprise that many scholars address the dynamics of DBMI (Hoßbach et al. 2016). Parida et al. (2019), for instance, state that a new demand emerging from digital technologies and business model innovation is to facilitate continuous improvement in order to keep up with competitors and customer demands. Others support this argument and highlight that digital business models constantly evolve over time (Gauthier et al. 2018; Bouncken et al. 2019; König et al. 2019; Katsamakas and Pavlov 2020; Li 2020) and that creating a successful DBMI is a journey (Weill and Woerner 2013). Being constantly on the move is particularly relevant in digital business models because they are in many cases transparent to all (Weill and Woerner 2013).

More recently, and against the backdrop of progressing digitalization, authors suggest that the right business model is not likely to be apparent from the onset (Cheah and Wang 2017; Priyono et al. 2020). König et al. (2019) conclude therefore that digital ventures, as opposed to non-digital ventures, iterate their business models to build the necessary product-market fit. Kohtamäki et al. (2019) even urge managers to continuously explore (digital) business model innovation as it is critical for survival. Following these observations, we argue that DBMIs are dynamic in nature and that dynamic is a defining attribute of the concept.

\subsection{DBMI requires changes in the key elements of the business model}

A common understanding in the reviewed literature is that a business model describes the overall logic of a firm, including the three key components of value proposition, value creation, and value capture. Business model innovation, then, involves changes in one or more of these components (Bourreau et al. 2012; Sorescu 2017; Bouncken et al. 2019; Kohtamäki et al. 2019; Laudien and Pesch 2019; Ghezzi and Cavallo 2020; Katsamakas and Pavlov 2020; Paiola and Gebauer 2020). Parida et al. (2019), for instance, emphasize the need for business model alignment by arguing that firms need to evaluate and understand their shortcomings in each of these key components and recognize that a change applied to one of them should always consider the other components. Kotarba (2018) offers an even more granular picture and shows how different waves of digitalization (wave 1: 1980-2000; wave 2: beyond 2000) have led to changes in key components of the well-known business model canvas. Others discuss how the transformative power of digitalization forces companies to adapt their business model logic (Wirtz et al. 2010; Veit et al. 2014; Rachinger et al. 2018; Cristofaro 2020).

Hence, regarding the changes in business model components, DBMI scholars rely heavily on traditional business model thinking (see Table 2). One reason for this is that there is currently no consensus about the key elements of digital business models. For example, El Sawy and Pereira (2013) propose the so-called VISOR framework, which encompasses a value proposition, an interface, a service platform, an operating model, and a revenue model. This framework has selectively been applied 
by other researchers, for instance by Remane et al. (2017). In contrast, Weill and Woerner (2013: 30) suggest three components of a digital business model, including content ("what is consumed?"), experience ("how is it packaged?"), and platform ("how is it delivered?"). While Blaschke et al. (2016) describe five components of a digital business model: people (digitally connected individuals/communities), businesses (digitally connected businesses/groups of businesses), things (digitally connected objects/smart things), data (real-time, complete, detailed, consistent, transparent, and accessible information), and a cloud (a value-creating service).

In sum, the literature review revealed that to date there is no consensus about the essential components that characterize digital business models. However, the underlying logic that changes in the essential components of a business model is a key attribute holds in the case of DBMI as well.

\subsection{DBMI entails transformation from analog to digital format}

The enabling role of digital technologies is extensively discussed in the recent literature on DBMI (Dellermann et al. 2017; Mihardjo et al. 2019; Li 2020; Sahut et al. 2020). For instance, Aagaard (2019) claims that the use of digital technologies is central to DBMI. A broad range of digital technologies is available for firms to make such a transformation. In the literature, there appears to be a consensus emerging about the classification of digital technologies, including automation (e.g., robotics, additive manufacturing, artificial intelligence), interaction (e.g., wearables, mobile Internet, apps, social media), intermediation (e.g., distributed ledgers, blockchain), data (e.g., big data, analytics, predictive algorithms), and connectivity (e.g., broadband, cloud computing, sensors).

This range of available digital technologies, however, is at the core of criticism about the definitional value of the concept of digital technologies for the construct of DBMI (Lanzolla et al. 2020a). Parida et al. (2019), for example, argue that the variety of technologies and their application make it challenging to use the concept. In order to avoid this conceptual pitfall concerning the definition of DBMI, and to broaden the debate, we thus refer to digitization in a rather basic sense. Several scholars in our sample affirm the perspective that digitization is about taking processes, content, or objects that used to be primarily (or entirely) physical or analog and transforming them to be primarily (or entirely) digital (Fichman et al. 2014; Loebbecke and Picot 2015; Bleicher and Stanley 2019; Bican and Brem 2020).

Although some argue that this interpretation of digital underestimates the farreaching implications of the construct (Kotarba 2018; Laudien and Pesch 2019), we believe that at this early point in research on DBMI, this kind of broad understanding allows for more inclusive, exploratory research, which is necessary to further develop the field.

\subsection{Proposing a novel definition}

Above, we have argued for the importance of construct clarity and have dissected extant definitions of the concept of DBMI. Subsequently, we have introduced and 
discussed key attributes of DBMI that emerged during a state-of-the-art literature review. Consolidating these attributes and building upon existing definitions, we propose the following novel definition of DBMI:

Digital business model innovation refers to purposeful, non-trivial, dynamic changes made to the key elements of the business model by transforming analog, physical objects, processes, or content into primarily (or entirely) digital formats.

This definition is consistent with our understanding of construct clarity, which is inspired by Suddaby (2010) and others (see above). We propose a somewhat broad, parsimonious definition for the concept that captures the essential properties and characteristics of the phenomenon under consideration without tautology or circularity. Furthermore, by tracing the foundation of these attributes, this novel definition contributes to higher levels of construct clarity when compared to existing definitions.

However, proposing a novel definition is only the first step toward developing a better understanding of the phenomenon in focus. As argued before, more scholarly research is needed into the antecedents, outcomes, and moderators of DBMI to provide more applicable insights for practitioners and managers. Therefore, below we discuss the issues embedded in such a definition of DBMI, why they deserve further research attention, and how such a definition as a whole can shape the future research agenda of DBMI, allowing the cross-fertilization of ideas from various management research fields.

\section{Discussion}

Proposing a new definition is a step forward toward enhanced construct clarity for DBMI. However, much future research is needed to explore and clarify underdeveloped issues related to the concept of DBMI. A new definition is a starting point that opens numerous doors for future research to address such gaps (e.g., Foss and Saebi 2017). We hereby discuss in detail the purpose, the non-triviality, and the dynamic change perspective, as well as the roles of digital technologies in DBMI research. In particular, we link our discussion to the broader fields of strategic management, information systems, and organization studies to expose the issue of DBMI to a wider audience.

\subsection{Purpose: what purpose and whose purpose?}

Our novel definition suggests that DBMI is a purposeful decision with a followup process based on deliberate intention. This view is consistent with the rational design perspective of strategy planning, which considers strategy as a deliberate and rational plan and ploy (Brews and Hunt 1999; Mintzberg 2003). However, the rational design perspective of strategy has been criticized for suffering from the fallacies of predetermination (where strategists are expected to predict what will 
happen), detachment (where strategies are made only by top management, who are detached from the business operations), and formalization (a misperception that simply following a formalized strategy process will lead to improved performance) (Mintzberg 1994).

This criticism of the rational design perspective of strategy planning is also relevant to the question regarding what the purpose of DBMI is at the initial point of departure. We observe two types of purposes, which may be equally effective at initiating a DBMI process but often lead to different paths of learning and development. First, in the case of start-ups with offerings that disrupt the market, it is often seen that the intention of digital disruption is to create new value propositions, address new customer needs, or define new strategies for value capture. Vivid examples are AirBnB's approach compared to the traditional hotel industry and Netflix in contrast with traditional video rental businesses. In these cases, digitalization is a means of realizing the purpose of creating a new business model. Such a purpose requires strategic thinking that can discover options that were previously unknown (Wack 1985; Heracleous 1998). Second, we also observe a common but less discussed starting point of deliberate intention, where a firm initially decides to simply digitize some parts of its operational process and tangible assets in response to competitive pressure and digital trends in the marketplace. Typical examples of this me too strategy are the retailers of consumer goods that initially followed the trend of supplementing their in-store sales by selling online. The purpose is to improve operational efficiency, where applying strategic planning is appropriate (Heracleous 1998; Wolf and Floyd 2017). It is likely that in the process of digitizing, a firm discovers that a more radical approach is needed to create new value and new customers and therefore explores new ways to capture value. This path of DBMI starts with a minimum level of purpose and follows an effectuation learning process. Such a case of DBMI reflects Mintzberg's fallacies regarding strategy planning: the purpose evolves, rather than being predetermined; the purpose might be driven by operations managers, rather than top management; and the purpose evolves as a result of double-loop learning, instead of following formal planning procedures.

This discussion reminds us to be sensible with regard to the interpretation of purpose in the definition of DBMI, allowing for strategic thinking, effectuation, and double-loop learning. This immediately opens up several interesting questions for future research. For instance, first, if the purpose of DBMI varies conceptually from a completely rational decision to create and capture new value to a full learning-bydoing intention, then which ambition levels of intention are the most effective and efficient, leading to the successful execution of DBMI? And under which conditions is one purpose better than another? If we cannot directly link the differences in purpose with firm financial performance, are we at least able to find some intermediary performance differences (e.g., time to reach the critical mass, speed of attracting and volume of venture finance, rate of converting paid customers) as the result of different types of purpose? Methodologically, another challenging question is whether and how we can determine the purpose ex post (especially in quantitative research using secondary data) and measure the ambition levels by assessing factors, such as initial investment, leadership commitment, and the involvement of business units. 
The differences in initial purpose are also relevant to a distinction between startups and established firms. How do they differ in terms of the purpose of DBMI? The former have no legacy and primarily need to adapt to external uncertainty (e.g., technological feasibility, the market, funding, and partnerships), while the latter operate based on their current business models and consider DBMI as a means to change their business as usual by exploring new opportunities. Established firms have a tendency to start with less ambitious purposes as they often get caught in the middle of exploitation and exploration (March 1991b; Li et al. 2008), so achieving DBMI may be a longer and more costly learning process, and they are likely to miss critical opportunities to form external partnerships (Chung et al. 2020). However, if these firms focus on the purpose of DBMI, then the obstacles are mainly from within, because the DBMI process entails inevitable organizational change (Vial 2019). Future research on the purpose of DBMI must therefore distinguish between (digitally-born) start-ups and established firms.

Regarding the issue of whose purpose, we make the following observations. The rational design perspective of strategy assumes that strategies are developed through top management deliberation. Criticized by Mintzberg for being an observed fallacy, emerging strategy focuses on the participation of middle managers in the strategy formation and planning process (Jarzabkowski and Balogun 2009; Wolf and Floyd 2017). In the case of DBMI, as its intention can differ at the initial phase and evolve during the process (Trischler et al. 2021), we expect middle managers to take an active role in reshaping the DBMI purpose. Some recent studies have suggested preliminary but promising insights into how to unleash the power of middle managers in the digitalization of services and digital transformation (Gjellebæk et al. 2020; Hermkens and Romme 2020). What is less understood is how the participation of middle managers interacts with top managers' cognition (Volberda et al. 2021) in the process of divergent and convergent thinking to redefine the purpose of DBMI.

Overall, we advise future research to specify with what kind of purpose and/or whose purpose a DBMI was initiated and outline any distinct stages of the effectuation process during the evolution of purpose. This is in general not too difficult to achieve in qualitative research, for example, by using multiple case study methods. It might, however, be challenging for quantitative research based on secondary data. Thus, we highly recommend that researchers using quantitative methods make extra efforts to dive deeper into the initial purpose of DBMI before drawing any conclusions from statistical results.

\subsection{Non-trivial: in which sense and for whom?}

The second attribute of our proposed definition of DBMI is the non-trivial aspect of change. Non-trivial novelty should be viewed from a value creation and value capture point of view instead of from the use of technology perspective because technologies alone do not create value. It is their use within a specific context that enables a firm to discover new ways of creating value and making changes (Hinings et al. 2018; Vial 2019). 
It is important to understand for whom DBMI has non-trivial novelty. First, DBMIs can disrupt entire industries. In that sense, the value that is created and captured is totally different from that of the industry's incumbents. As mentioned above, these cases rarely occur. Recent discussions between practitioners about ecosystem innovation suggest that firms revolutionize their business models by considering how new value points can be created, controlled, and monetized within an ecosystem, which involves different customers, suppliers, third-party partners, and other stakeholders (Chung et al. 2020; Dietz et al. 2020). Thus, the ecosystem innovation approach may be one of the ways through which DBMI leads to non-trivial change in an industry. However, implementing the ecosystem innovation approach is one thing, but the outcome of a firm doing so (the realized DBMI) may or may not eventually be novel and non-trivial for the industry. Here, it is sensible to distinguish between the non-triviality of novelty as an attempt or intention and the non-triviality of novelty as an outcome.

Second, the attribute of the non-triviality of novelty can also be viewed from a firm perspective. That is, DBMI is novel and non-trivial for the firm undertaking it. This discussion is closely related to the dilemma of exploitation and exploration, where it is important for established firms to exploit the efficiency of existing business models and explore new business opportunities that depart from the existing ones (March 1991b; Li et al. 2008). When a firm takes a radical approach toward DBMI that departs significantly from its existing business model but is not new to the industry, can we still consider it as non-trivial? On the one hand, a positive view advocates that as long as the firm creates new value, implements new forms of value capture (monetizing), and commits significant resources to the corresponding organizational change in structure, process, and even culture, it is surely implementing non-trivial DBMI. On the other hand, an opposing view may argue that it depends on whether the firm makes significant changes to its operational models and new value creation simultaneously (Berman 2012) and to what extent the firm experiments with different types of search and the recombination of knowledge, resources, and capabilities during the digitalization process (Lanzolla et al. 2020b). However, limited empirical research aims to clarify the definition of non-trivial, even though most researchers agree that DBMI needs to have this characteristic.

A clear understanding of non-trivial novelty is important to distinguish DBMI from digital transformation (Hinings et al. 2018; Vial 2019): while DBMI inevitably results in a certain level of digital transformation, the latter can be deployed by an established firm without creating a new business model. As the literature on digital transformation has converged toward a common understanding that digital transformation entails structural, process, and cultural change in an organization through combinations of information, computing, communication, and connectivity technologies (Vial 2019), so does non-trivial DBMI. Thus, without a clear understanding of the non-triviality that defines DBMI, it will be impossible to separate the impact of DBMI from that of digital transformation on firm performance. This is another promising but challenging topic for future research.

Overall, we advise future research to (1) consider non-trivial novelty from a value creation and value capture point of view instead of from the use of technology perspective; (2) distinguish between the non-triviality of novelty as an attempt 
or intention and the non-triviality of novelty as an outcome; and (3) specify whether non-trivial novelty is observed from an industry or from a focal firm perspective so that readers have a clear reference point.

\subsection{Dynamic change: the learning organization}

Another key attribute of the DBMI definition suggests that the concept is a dynamic process of changing business model elements. For instance, Berman (2012) describes three pathways of digital transformation: based on the value creation dimension, grounded in the operational dimension, and leading to DBMI. Hinings et al. (2018) suggest that digital transformation has implications for institutional and organizational change as a result of digital transformation at organization and ecosystem levels. But how does such a dynamic process take place and what theoretical foundation can researchers rely on? First, we agree with Vial (2019) that one promising direction for future research on the dynamism of DBMI is to look into how organizations build dynamic capabilities to utilize and develop digital technologies, support digital ecosystems, and create new value. It is also important to research in detail the micro-foundations of dynamic capabilities needed for DBMI in daily practice (Teece 2007).

More fundamentally, we suggest that scholars design new research that builds on the behavioral theory of organization (Cyert and March 1992). Indeed, central to achieving sustainable competitive advantages is adaptation to the changing business environment. The notion of dynamic is devoted to the continuous renewal of organizational resources and capabilities, thereby matching the demands of changing environments. Thus, researchers interested in the dynamics of DBMI need to pay attention to how organizations learn and adapt. The behavioral theory of organizations has long recognized that due to bounded rationality, decision makers have access to limited information, formulating a partial presentation of problems, and they search for information that is constrained by managers' cognition space based on their prior experience, aspiration levels, and an organization's resource slack (Levinthal and March 1981; March 1991a; Simon 1991). Entrepreneurs and managers subjectively acquire a new problem presentation, which signals unmet customer needs or unfulfilled business potential that justifies a new business model opportunity. As the preliminary problem presentation is based on limited information, there is a great deal of unknown information to search for, sense, evaluate, and learn from. This process takes place through the interplay between experimental learning and experiential learning (Argyris 1976). Experimental learning involves trial-and-error experimentations where individuals and teams try out new, unfamiliar practices, detect deviations from established mental rules, and adjust their actions accordingly without questioning the fundamental goals, assumptions, and meanings (so-called singleloop learning). Experiential learning is built on the accumulation of the feedforward of experimental learning, based on which individuals and teams consciously question and challenge the fundamental goals, assumptions, and meanings (so-called double-loop learning). The repetition of experimental learning becomes experience, which, in turn, provides feedback to guide new experimentations. Therefore, some 
scholars argue that dynamic capability is a multi-level concept (Collis 1994): (1) First-order dynamic capabilities include the ability to sense and seize opportunities and reconfigure the resources of a business model. There are various organizational learning routines that need to be responsive to the dynamism in external environments. (2) Second-order dynamic capabilities to monitor changes in the first-order dynamic capabilities and orchestrate them as a whole (Zollo and Winter 2002; Schilke 2014).

We have no reason to expect the dynamic learning process of DBMI to deviate from the virtuous circle of single-loop and double-loop learning, as some prior studies on business model innovation have suggested clear evidence in this respect (Sabatier, Mangematin, and Rousselle 2010). However, it will be interesting but challenging to find out whether processes of dynamic capabilities development can be accelerated by digital transformation and the accumulation of digital dynamic capabilities through the repeated practices of single-loop and double-loop learning (Warner and Wäger 2019). In other words, will experimental (single-loop) learning become faster, and will experiential (double-loop) learning become more effective as a result of continuous digital transformation? This inquiry makes intuitive sense but lacks empirical evidence. In addition, the implementation of a dynamic learning process is probably set by a firm's initial intention/purpose. Thus, how much of a DBMI's success can be attributed to the initial status of intention/purpose as opposed to the dynamic learning process? Future research can also investigate this research question. Moreover, prior research has suggested that small firms and startups may also deploy coopetition strategy to enhance performance (Roig-Tierno et al. 2018). We believe a promising direction for future research will be to investigate the dynamic capabilities required by small firms' and start-ups' coopetition strategy through DBMI.

\subsection{Digital technologies: duality in two different senses}

The definition of DBMI suggests a transformation of analog assets and processes into digital formats. We suggest that digital technologies play dual roles in two different senses during this transformation. First, digital technologies can enable and/or constrain new value creation and capture. On the enabling side, firms can use automation, interaction, intermediation, data, or connectivity technologies to fuel disruptive DBMI (Karimi and Walter 2015; Sebastian et al. 2017). Companies can tap into a pool of unprecedented technological advancements and select those relevant for the realization of their DBMI. Thus, the enabling role provides a digital resource bundle that companies can select, utilize, and/or further develop. However, on the constraining side, the unavailability of certain digital technologies (e.g., a 5G network) and the lack of accessibility to complementary technologies (e.g., advanced motion sensory technologies) could make such digital technologies less useful for disruptive DBMI (e.g., the technological obstacles to making driverless vehicles), while the fast pace of digital technology development may make a firm's investment 
in digital technologies riskier or effective for shorter time periods than anticipated (Kuk and Janssen 2013).

Second, digital technologies can also shape the context in which the availability of an overall pool of digital technologies, the future trends of digital technology development, and the best practices of industry leaders with respect to applying digital technologies to DBMI jointly form informational cues to be interpreted by managers-either as opportunities to undertake or threats that prohibit DBMI. In other words, the second sense of duality with regard to digital technologies is that they can be direct enablers and/or constraints for DBMI, while simultaneously creating a triggering context in which the purpose-making of DBMI might emerge. The contextual role of digital technologies, thus, opens up a new direction for future research about how the digital context intertwines with other contextual factors, such as business, social, spatial, and institutional ones (Welter 2011). This line of inquiry will also be relevant for future entrepreneurship research because the dual role of technologies will shape a new opportunity landscape for starting new businesses (Kraus et al. 2019b).

Table 4 summarizes the key issues discussed above by describing the pending problems to be resolved by future research. It also indicates how they are related to each other and which supporting literature might be useful for developing hypotheses.

\subsection{Limitations}

Our work has some limitations. First, the sample size included in this review is limited. Given the immature nature of the field focused on by this study, this is not a surprise. However, digitalization and digital transformation, as well as DBMI, are very popular topics (Vial 2019; Vaska et al. 2021) with an increasing number of contributions to academic and practitioner conferences. Although these conference proceedings may potentially provide relevant insights for our study, they were excluded from our review because of a lack of rigid peer-review processes. Second, our approach to searching for relevant literature was limited to publications in English with full-text access to a $p d f$ file format. Consequently, research contributions in other languages were not included in this study. In particular, research from Asia is under-represented, despite its significant digital advancements in recent years (Vaska et al. 2021). Finally, the selection of the search terms presents another limitation of this study, as business model innovation is sometimes also referred to as modifications, adjustments, or changes, amongst others. However, by applying two different search strategies, we intended to minimize the extent of this limitation. 


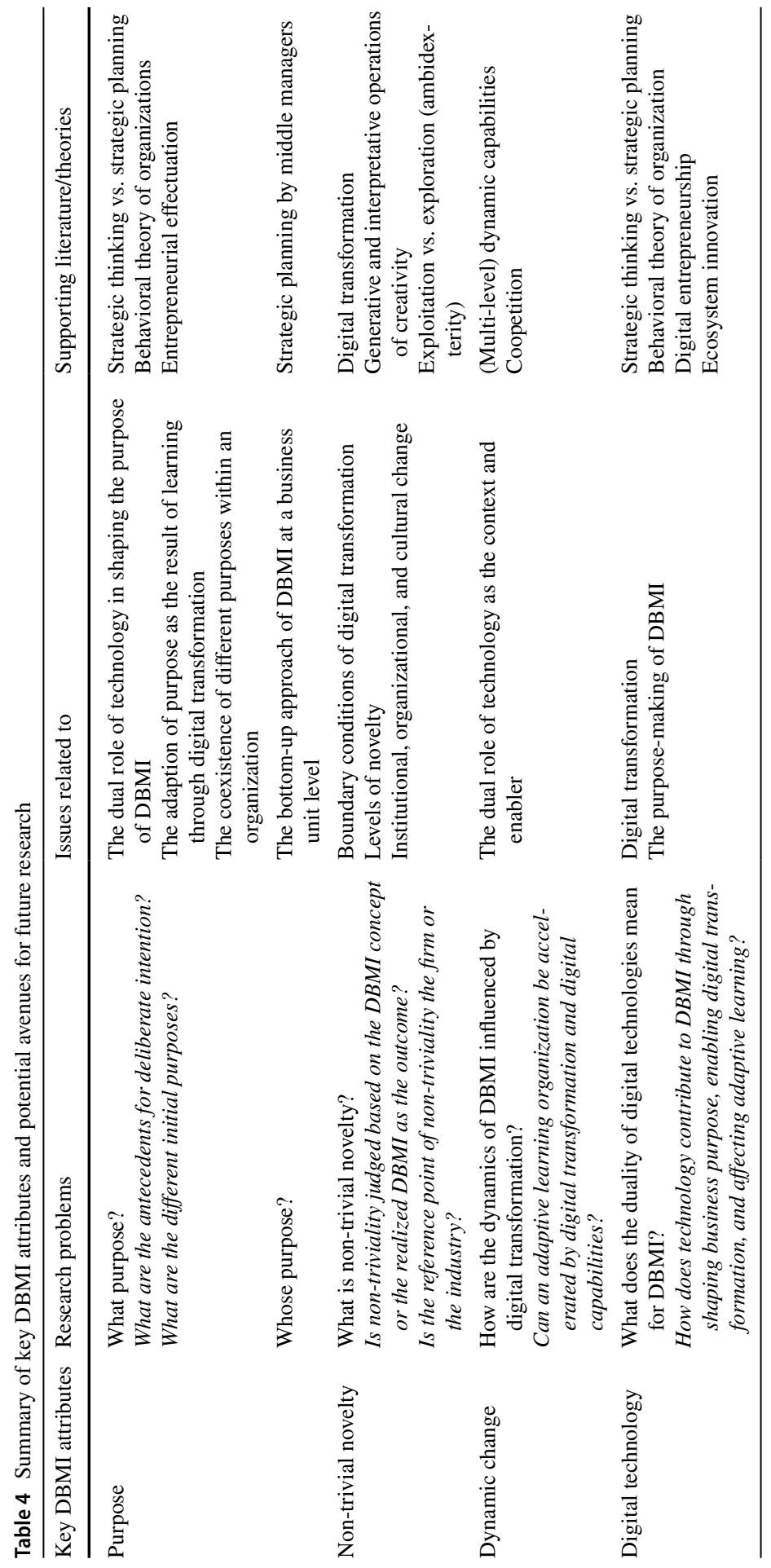




\section{Conclusion}

Digital and digitalization shape a fundamental transformation of business, which is calling for novel theorizing (Yoo et al. 2012; El Sawy and Pereira 2013; Nambisan 2017; Lanzolla et al. 2020a) and new conceptual contributions to the literature (Breslin et al. 2020). In this paper, we conducted a targeted, state-of-the-art literature review of 57 significant publications dealing with the concept of DBMI. We developed an understanding of the importance of construct clarity and applied it when critically reviewing the extant definitions in this field. Building on our observations and reflections, we proposed a novel definition for the concept, in which purposeful, non-triviality, dynamic change, and digitalization are the key attributes. With this definition, we are able to propose a set of research avenues that deserve future attention and may push the boundary at the intersection of DBMI, digital transformation, and strategic management.

Acknowledgements The authors are grateful to the grant support made by the Spar Nord Foundation in Denmark.

Funding The funding was provided by Spar Nord Fonden (Grant 06-07-2018).

Open Access This article is licensed under a Creative Commons Attribution 4.0 International License, which permits use, sharing, adaptation, distribution and reproduction in any medium or format, as long as you give appropriate credit to the original author(s) and the source, provide a link to the Creative Commons licence, and indicate if changes were made. The images or other third party material in this article are included in the article's Creative Commons licence, unless indicated otherwise in a credit line to the material. If material is not included in the article's Creative Commons licence and your intended use is not permitted by statutory regulation or exceeds the permitted use, you will need to obtain permission directly from the copyright holder. To view a copy of this licence, visit http://creativecommons.org/licen ses/by/4.0/.

\section{References}

Aagaard A (2019) Digital business models driving transformation and innovation. Palgrave Macmillan, Cham

Argyris C (1976) Single-loop and double-loop models in research on decision making. Adm Sci Q 21:363-375

Aversa P, Haefliger S, Hueller F, Reza DG (2020) Customer complementarity in the digital space: exploring Amazon's business model diversification. Long Range Plann. https://doi.org/10. 1016/j.lrp.2020.101985

Berman SJ (2012) Digital transformation: opportunities to create new business models. Strateg Leadersh 40:16-24. https://doi.org/10.1108/10878571211209314

Berman SJ, Korsten PJ, Marshall A (2016) A four-step blueprint for digital reinvention. Strateg Leadersh 44:18-25. https://doi.org/10.1108/SL-06-2016-0042

Bican PM, Brem A (2020) Digital business model, digital transformation, digital entrepreneurship: Is there a sustainable "digital"? Sustainability 12:1-15. https://doi.org/10.3390/su12135239

Blaschke M, Cigaina M, Riss UV, Shoshan I (2016) Designing business models for the digital economy. In: Oswald G, Kleinemeier M (eds) Shaping the digital enterprisetrends and use cases in digital innovation and transformation. Springer International Publishing, Berlin, pp 121-136

Bleicher J, Stanley H (2019) Digitization as a catalyst for business model innovation a three-step approach to facilitating economic success. J Bus Manag 5:62-71 
Bouncken RB, Kraus S, Roig-Tierno N (2019) Knowledge-and innovation-based business models for future growth: digitalized business models and portfolio considerations. Rev Manag Sci. https://doi.org/10.1007/s11846-019-00366-z

Bourreau M, Gensollen M, Moreau F (2012) The impact of a radical innovation on business models: incremental adjustments or big bang? Ind Innov 19:415-435. https://doi.org/10.1080/13662716. 2012.711026

Bouwman H, Nikou S, de Reuver M (2019) Digitalization, business models, and SMEs: How do business model innovation practices improve performance of digitalizing SMEs? Telecomm Policy 43:1-18. https://doi.org/10.1016/j.telpol.2019.101828

Braun V, Clarke V (2006) Using thematic analysis in psychology. Qual Res Psychol 3:77-101. https:// doi.org/10.1017/CBO9781107415324.004

Breslin D, Gatrell C, Bailey K (2020) Developing insights through reviews: reflecting on the 20th anniversary of the international journal of management reviews. Int J Manag Rev 22:3-9. https://doi.org/10.1111/ijmr.12219

Brews P, Hunt J (1999) Learning to plan and planning to learn: resolving the planning school/learning school debate. Strateg Manag J 913:889-913

Casadesus-Masanell R, Ricart JE (2010) From strategy to business models and onto tactics. Long Range Plann 43:195-215. https://doi.org/10.1016/j.lrp.2010.01.004

Cavalcante SA (2014) Preparing for business model change: the "pre-stage" finding. J Manag Gov 18:449-469. https://doi.org/10.1007/s10997-012-9232-7

Cheah S, Wang S (2017) Big data-driven business model innovation by traditional industries in the Chinese economy. J Chin Econ For Trade Stud 10:229-251. https://doi.org/10.1108/ JCEFTS-05-2017-0013

Chung V, Dietz M, Rab I, Townsend Z (2020) Ecosystem 2.0: Climbing to the next level. McKinsey Digit. https://www.mckinsey.com/business-functions/mckinsey-digital/our-insights/ecosystem2-point-0-climbing-to-the-next-level. Accessed 15 Mar 2021

Collis DJ (1994) Research note: how valuable are organizational capabilities? Strateg Manag J 15:143-152. https://doi.org/10.1002/smj.4250150910

Cristofaro M (2020) E-business evolution: an analysis of mobile applications' business models. Technol Anal Strateg Manag 32:88-103. https://doi.org/10.1080/09537325.2019.1634804

Cyert R, March JG (1992) A behavioral theory of the firm, 2nd edn. Wiley, Blackwell

DaSilva CM (2018) Understanding business model innovation from a practitioner perspective. J Bus Model 6:19-24. https://doi.org/10.5278/ojs.jbm.v6i2.2456

DaSilva CM, Trkman P (2014) Business model: What it is and what it is not. Long Range Plann 47:379-389. https://doi.org/10.1016/j.1rp.2013.08.004

Dellermann D, Fliaster A, Kolloch M (2017) Innovation risk in digital business models: the German energy sector. J Bus Strateg 38:35-43. https://doi.org/10.1108/JBS-07-2016-0078

Dietz M, Khan H, Rab I (2020) How do companies create value from digital ecosystems? McKinsey Digit. https://www.mckinsey.com/business-functions/mckinsey-digital/our-insights/how-do-compa nies-create-value-from-digital-ecosystems. Accessed 15 Mar 2021

Ehret M, Wirtz J (2017) Unlocking value from machines: business models and the industrial internet of things industrial internet of things. J Mark Manag 33:111-130. https://doi.org/10.1080/0267257X. 2016.1248041

El Sawy OA, Pereira F (2013) Business modelling in the dynamic digital space: an ecosystem approach. Springer, Berlin Heidelberg

Fichman RG, Dos Santos BL, Zheng Z (Eric) (2014) Digital innovation as a fundamental and powerful concept in the information systems curriculum. MIS Q vol. 38: pp. 329-343. Doi: https://doi.org/ 10.25300/MISQ/2014/38.2.01

Foss NJ, Saebi T (2017) Fifteen years of research on business model innovation: how far have we come, and where should we go? J Manage 43:200-227. https://doi.org/10.1177/0149206316675927

Foss NJ, Saebi T (2018) Business models and business model innovation: between wicked and paradigmatic problems. Long Range Plann 51:9-21. https://doi.org/10.1016/j.lrp.2017.07.006

Gassmann O, Frankenberger K, Sauer R (2016) Exploring the field of business model innovation: new theoretical perspectives. Springer International Publishing, Cham

Gauthier C, Bastianutti J, Haggège M (2018) Managerial capabilities to address digital business models : the case of digital health. Strateg Chang 27:173-180. https://doi.org/10.1002/jsc.2192

George G, Bock AJ (2011) The business model in practice and its implications for entrepreneurship research. Entrep Theory Pract 35:83-111. https://doi.org/10.1111/j.1540-6520.2010.00424.x 
Ghezzi A, Cavallo A (2020) Agile business model innovation in digital entrepreneurship: lean startup approaches. J Bus Res 110:519-537. https://doi.org/10.1016/j.jbusres.2018.06.013

Gjellebæk C, Svensson A, Bjørkquist C et al (2020) Management challenges for future digitalization of healthcare services. Futures 124:102636. https://doi.org/10.1016/j.futures.2020.102636

Goertz G (2006) Chapter three: concept intensions and extensions. Social science concepts: a user's guide. Princeton University Press, New Jersey, pp 69-94

Gong C, Ribiere V (2021) Developing a unified definition of digital transformation. Technovation 102:102217. https://doi.org/10.1016/j.technovation.2020.102217

Grant MJ, Booth A (2009) A typology of reviews : an analysis of 14 review types and. Health Info Libr J 26:91-108. https://doi.org/10.1111/j.1471-1842.2009.00848.x

Hanelt A, Bohnsack R, Marz D, Antunes Marante C (2020) A systematic review of the literature on digital transformation: insights and implications for strategy and organizational change. J Manag Stud. https://doi.org/10.1111/joms.12639

Heracleous L (1998) Strategic thinking or strategic planning? Long Range Plann 31:481-487. https://doi. org/10.1016/S0024-6301(98)80015-0

Hermkens F, Romme AG (2020) The role of middle management in continuous improvement: the Bermuda Triangle of Leadership, implementation and behavioral change. J Manag Policies Pract. https://doi.org/10.15640/jmpp.v8n1a5

Hinings B, Gegenhuber T, Greenwood R (2018) Digital innovation and transformation: an institutional perspective. Inf Organ 28:52-61. https://doi.org/10.1016/j.infoandorg.2018.02.004

Hoßbach N, Wiener M, Saunders CS (2016) The unfolding of value sources during online business model transformation. J Bus Model 4:22-41. https://doi.org/10.5278/ojs.jbm.v4i2.1623

Jarzabkowski P, Balogun J (2009) The practice and process of delivering integration through strategic planning. J Manag Stud 46:1255-1288. https://doi.org/10.1111/j.1467-6486.2009.00853.x

Karimi J, Walter Z (2015) The role of dynamic capabilities in responding to digital disruption : a factorbased study of the newspaper industry. J Manag Inf Syst 32:39-81. https://doi.org/10.1080/07421 222.2015.1029380

Katsamakas E, Pavlov OV (2020) AI and business model innovation: leveraging the AI feedback loop. J Bus Model 8:22-30. https://doi.org/10.2139/ssrn.3554286

Klang D, Wallnöfer M, Hacklin F (2014) The business model paradox : a systematic review and exploration of antecedents. Int J of Manag Rev. 16:454-478. https://doi.org/10.1111/ijmr.12030

Kohli R, Melville NP (2019) Digital innovation: a review and synthesis. Inf Syst J 29:200-223. https:// doi.org/10.1111/isj.12193

Kohtamäki M, Parida V, Oghazi P et al (2019) Digital servitization business models in ecosystems: a theory of the firm. J Bus Res 104:380-392. https://doi.org/10.1016/j.jbusres.2019.06.027

König M, Ungerer C, Baltes G, Terzidis O (2019) Different patterns in the evolution of digital and nondigital ventures' business models. Technol Forecast Soc Change 146:844-852. https://doi.org/10. 1016/j.techfore.2018.05.006

Kotarba M (2018) Digital transformation of business models. Found Manag 10:123-142. https://doi.org/ 10.2478/fman-2018-0011

Kraus S, Palmer C, Kailer N et al (2019a) Digital entrepreneurship: a research agenda on new business models for the twenty-first century. Int J Entrep Behav Res 25:353-375. https://doi.org/10.1108/ IJEBR-06-2018-0425

Kraus S, Roig-Tierno N, Bouncken RB (2019b) Digital innovation and venturing: an introduction into the digitalization of entrepreneurship. Rev Manag Sci 13:519-528. https://doi.org/10.1007/ s11846-019-00333-8

Kraus S, Breier M, Dasí-Rodríguez S (2020) The art of crafting a systematic literature review in entrepreneurship research. Int Entrep Manag J 16:1023-1042

Kuk G, Janssen M (2013) Assembling infrastructures and business models for service design and innovation. Inf Syst J 23:445-469. https://doi.org/10.1111/j.1365-2575.2012.00418.x

Lambert SC, Davidson RA (2013) Applications of the business model in studies of enterprise success, innovation and classification: an analysis of empirical research from 1996 to 2010. Eur Manag J 31:668-681. https://doi.org/10.1016/j.emj.2012.07.007

Lanzolla G, Lorenz A, Miron-Spektor E et al (2020a) Digital transformation: what is new if anything? Emerging patterns and management research. Acad Manag Discov 6:341-350. https://doi.org/10. 5465/amd.2020.0144 
Lanzolla G, Pesce D, Tucci CL (2020b) The digital transformation of search and recombination in the innovation function: tensions and an integrative framework. J Prod Innov Manag. https://doi.org/ 10.1111/jpim. 12546

Laudien SM, Pesch R (2019) Understanding the influence of digitalization on service firm business model design: a qualitative-empirical analysis. Rev Manag Sci 13:575-587. https://doi.org/10. 1007/s11846-018-0320-1

Levinthal D, March JG (1981) A model of adaptive organizational search. J Econ Behav Organ 2:307333. https://doi.org/10.1016/0167-2681(81)90012-3

Li F (2020) The digital transformation of business models in the creative industries: a holistic framework and emerging trends. Technovation 92-93:102012. https://doi.org/10.1016/j.technovation.2017.12. 004

Li Y, Vanhaverbeke W, Schoenmakers W (2008) Exploration and exploitation in innovation: Reframing the interpretation. Creat Innov Manag 17:107-126. https://doi.org/10.1111/j.1467-8691.2008. 00477.x

Li L, Su F, Zhang W, Mao JY (2017) Digital transformation by SME entrepreneurs: A capability perspective. Inf Syst J. https://doi.org/10.1111/isj.12153

Linde L, Sjödin D, Parida V, Gebauer H (2021) Evaluation of Digital Business Model Opportunities: A Framework for Avoiding Digitalization Traps. Res Technol Manag 64:43-53. https://doi.org/10. 1080/08956308.2021.1842664

Loebbecke C, Picot A (2015) Reflections on societal and business model transformation arising from digitization and big data analytics: A research agenda. J Strateg Inf Syst 24:149-157. https://doi. org/10.1016/j.jsis.2015.08.002

March JG (1991a) How Decisions Happen in Organizations. Human-Computer Interact 6:95-117. https:// doi.org/10.1007/978-3-030-28987-4_12

March JG (1991b) Exploration and Exploitation in organizational learning. Organ Sci 2:71-88

Martín-Peña ML, Díaz-Garrido E, Sánchez-López JM (2018) The digitalization and servitization of manufacturing : A review on digital business models *. Strateg Chang 27:91-99. https://doi.org/10. $1002 /$ jsc. 2184

Massa L, Tucci CL, Afuah A (2017) A critical assessment of business model research. Acad Manag Ann 11:73-104. https://doi.org/10.5465/annals.2014.0072

Matt C, Hess T, Benlian A (2015) Digital Transformation Strategies. Bus Inf Syst Eng 57:339-343. https://doi.org/10.1007/s12599-015-0401-5

Mihardjo LWW, Sasmoko S, Alamsjah F, Elidjen E (2019) Digital leadership role in developing business model innovation and customer experience orientation in industry 4.0. Manag Sci Lett 9:17491762. https://doi.org/10.5267/j.msl.2019.6.015

Mintzberg H (1994) The fall and rise of strategic planning. Harv Bus Rev 72:107-114

Mintzberg H (2003) Five Ps for Strategy. In: Mintzberg H, Lampe J, Quinn JB, Ghosal S (eds) The Strategy Process: Concepts, Contexts, Cases, 2nd edn. Pearson Education Limited, Essex, pp 3-9

Morabito V (2014) Reinventing Business Models: The Third Way of Digital Innovation. In: Trends and Challenges in Digital Business Innovation. Springer International Publishing, pp 165-186

Morkunas VJ, Paschen J, Boon E (2019) How blockchain technologies impact your business model. Bus Horiz 62:295-306. https://doi.org/10.1016/j.bushor.2019.01.009

Munck GL, Verkuilen J (2002) Conceptualizing and measuring democracy: Evaluating alternative indices. Comp Polit Stud 35:5-34. https://doi.org/10.1177/001041400203500101

Nambisan S (2017) Digital Entrepreneurship: Toward a Digital Technology Perspective of Entrepreneurship. Entrep Theory Pract 41:1029-1055. https://doi.org/10.1111/etap.12254

Paiola M, Gebauer H (2020) Internet of things technologies, digital servitization and business model innovation in BtoB manufacturing firms. Ind Mark Manag 89:245-264. https://doi.org/10. 1016/j.indmarman.2020.03.009

Parida V, Sjödin D, Reim W (2019) Reviewing Literature on Digitalization, Business Model Innovation, and Sustainable Industry : Past Achievements and Future Promises. Sustainability 11:118. https://doi.org/10.3390/su11020391

Parmigiani A, King E (2019) Successfully Proposing and Composing Review Papers. J Manage 45:3083-3090. https://doi.org/10.1177/0149206319874875

Pateli AG, Giaglis GM (2005) Technology innovation-induced business model change : a contingency approach. J Organ Chang Manag 18:167-183. https://doi.org/10.1108/09534810510589589

Patton MQ (1990) Qualitative evaluation and research methods, 2nd edn. SAGE Publications, Inc., Newbury Park, CA 
Priyono A, Moin A, Putri VNAO (2020) Identifying Digital Transformation Paths in the Business Model of SMEs during the COVID-19 Pandemic. J Open Innov Technol Mark Complex 6:1-22

Rachinger M, Rauter R, Müller C et al (2018) Digitalization and its influence on business model innovation. J Manuf Technol Manag. https://doi.org/10.1108/JMTM-01-2018-0020

Remane G, Hanelt A, Nickerson RC, Kolbe LM (2017) Discovering digital business models in traditional industries. J Bus Strategy 38:41-51. https://doi.org/10.1108/JBS-10-2016-0127

Joseph RP (2018) Digital transformation, business model innovation and efficiency in content industries: a review. Int Tech Manag Rev 7(1):59-70. https://doi.org/10.2991/itmr.7.1.6

Roig-Tierno N, Kraus S, Cruz S (2018) The relation between coopetition and innovation/entrepreneurship. Rev Manag Sci 12:379-383. https://doi.org/10.1007/s11846-017-0266-8

Sahut JM, Dana LP, Laroche M (2020) Digital innovations, impacts on marketing, value chain and business models: An introduction. Can J Adm Sci 37:61-67. https://doi.org/10.1002/cjas.1558

Sarasvathy SD (2001) Causation and effectuation : toward a theoretical shift from economic inevitability to entrepreneurial contingency. Acad Manag Rev 26:243-263

Schallmo D, Williams CA, Boardman L (2017) Digital transformation of business models-best practice, enablers, and roadmap. Int J Innov Manag 21:1740014. https://doi.org/10.1142/s1363 $91961740014 x$

Schallmo D, Williams CA (2018) Digital transformation of business models. In: Schallmo D, Williams CA (eds) Digital transformation now! Springer, Cham, Switzerland, pp 9-13

Schilke O (2014) Second-order dynamic capabilities: How do they matter? Acad Manag Perspect 28:368-380. https://doi.org/10.5465/amp.2013.0093

Schoemaker PJH, Heaton S, Teece D (2018) Innovation, dynamic capabilities, and leadership. Calif Manage Rev 61:15-42. https://doi.org/10.1177/0008125618790246

Sebastian IM, Moloney KG, Ross JW et al (2017) How big old companies navigate digital transformation. MIS Q Exec 16:197-213

Sharma P, Chrisman SJJ (1999) Toward a reconciliation of the definitional issues in the field of corporate entrepreneurship. Entrep Concepts Theory Perspect. https://doi.org/10.1007/ 978-3-540-48543-8_4

Simon HA (1991) Bounded rationality and organizational learning. Organ Sci 2:125-134. https://doi. org/10.1162/152417399570142

Sorescu A (2017) Data-driven business model innovation. J Prod Innov Manag 34:691-696. https:// doi.org/10.1111/jpim. 12398

Standing C, Mattsson J (2018) Fake it until you make it : business model conceptualization in digital entrepreneurship. J Strateg Mark 4488:1-15. https://doi.org/10.1080/0965254X.2016.1240218

Suddaby R (2010) Editor 's comments: construct clarity in theories. Acad Manag Rev 35:346-357. https://doi.org/10.5465/AMR.2010.51141319

Teece DJ (2007) Explicating dynamic capabilities: the nature and microfoundations of (sustainable) enterprise performance. Strateg Manag J 28:1319-1350. https://doi.org/10.1002/smj

Teece DJ (2010) Business models, business strategy and innovation. Long Range Plann 43:172-194. https://doi.org/10.1016/j.lrp.2009.07.003

Teece DJ, Linden G (2017) Business models, value capture, and the digital enterprise. J Organ Des 6:1-14. https://doi.org/10.1186/s41469-017-0018-x

Trischler M, Meier P, Trabucchi D (2021) Digital platform tactics: how to implement platform strategy over time. J Bus Model 9:67-76. https://doi.org/10.5278/jbm.v9i1.5908

Vaska S, Massaro M, Bagarotto EM, Dal Mas F (2021) The digital transformation of business model innovation: a structured literature review. Front Psychol. https://doi.org/10.3389/fpsyg.2020. 539363

Veit D, Clemons E, Benlian A et al (2014) Business models: an information systems research agenda. Bus Inf Syst Eng 6:45-53. https://doi.org/10.1007/s12599-013-0308-y

Venkatesh R, Mathew L, Singhal TK (2019) Imperatives of business models and digital transformation for digital services providers. Int J Bus Data Commun Netw 15:105-124. https://doi.org/10.4018/ IJBDCN.2019010107

Vial G (2019) Understanding digital transformation: a review and a research agenda. J Strateg Inf Syst 28:118-144. https://doi.org/10.1016/j.jsis.2019.01.003

Volberda HW, Khanagha S, Baden-Fuller C et al (2021) Strategizing in a digital world: overcoming cognitive barriers, reconfiguring routines and introducing new organizational forms. Long Range Plann 54:102110. https://doi.org/10.1016/j.lrp.2021.102110

Wack P (1985) Scenarios: uncharted waters ahead. Harv Bus Rev September-October:72-89 
Wacker JG (2004) A theory of formal conceptual definitions: developing theory-building measurement instruments. J Oper Manag 22:629-650. https://doi.org/10.1016/j.jom.2004.08.002

Warner KSR, Wäger M (2019) Building dynamic capabilities for digital transformation: an ongoing process of strategic renewal. Long Range Plann 52:326-349. https://doi.org/10.1016/j.lrp.2018.12.001

Webster J, Watson RT (2002) Analyzing the past to prepare for the future: writing a literature review. MIS Q 26:xiii-xxiii

Weill P, Woerner S (2013) Optimizing your digital business model. MIT Sloan Manag Rev 54:71-78. https://doi.org/10.1109/EMR.2015.7059380

Welter F (2011) Contextualizing entrepreneurship—conceptual challenges and ways forward. Entrep Theory Pract 35:165-184. https://doi.org/10.1111/j.1540-6520.2010.00427.x

Wirtz BW, Schilke O, Ullrich S (2010) Strategic development of business models: Implications of the web 2.0 for creating value on the internet. Long Range Plann 43:272-290. https://doi.org/10. 1016/j.1rp.2010.01.005

Wirtz BW, Pistoia A, Ullrich S, Göttel V (2016) Business models: origin, development and future research perspectives. Long Range Plann 49:36-54. https://doi.org/10.1016/j.lrp.2015.04.001

Wolf C, Floyd SW (2017) Strategic planning research: toward a theory-driven agenda. J Manag 43(6):1754-1788. https://doi.org/10.1177/0149206313478185

Wolfswinkel JF, Furtmueller E, Wilderom CPM (2013) Using grounded theory as a method for rigorously reviewing literature. Eur J Inf Syst 22:45-55. https://doi.org/10.1057/ejis.2011.51

Xu Y, Koivumäki T (2019) Digital business model effectuation: an agile approach. Comput Human Behav 95:307-314. https://doi.org/10.1016/j.chb.2018.10.021

Yoo Y, Henfridsson O, Lyytinen K (2010) The new organizing logic of digital innovation: an agenda for information systems research. Inf Syst Res 21:724-735. https://doi.org/10.1287/isre.1100.0322

Yoo Y, Boland RJ, Lyytinen K, Majchrzak A (2012) Organizing for innovation in the digitized world. Organ Sci 23:1398-1408. https://doi.org/10.1287/orsc.1120.0771

Zollo M, Winter SG (2002) Deliberate learning and the evolution of dynamic capabilities. Organ Sci 13:339-351. https://doi.org/10.1287/orsc.13.3.339.2780

Zott C, Amit R (2017) Business model innovation: how to create value in a digital world. GfK Mark Intell Rev 9:18-23. https://doi.org/10.1515/gfkmir-2017-0003

Publisher's Note Springer Nature remains neutral with regard to jurisdictional claims in published maps and institutional affiliations. 